\title{
INSTITUIÇÕES, MUDANÇA TECNOLÓGICA E CRESCIMENTO ECONÔMICO: UMA APROXIMAÇÃO DAS ESCOLAS EVOLUCIONÁRIAS NEO-SCHUMPETERIANA E NEO-INSTITUCIONALISTA
}

\author{
Jonattan Rodriguez Castelli ${ }^{1}$ \\ Octavio Augusto Camargo Conceição ${ }^{2}$
}

Resumo: o objetivo deste artigo é fazer uma aproximação do escopo teórico de duas correntes do pensamento econômico, tentando demonstrar a estrita relação entre mudança técnica e mudança institucional e de que forma a interação entre elas determina a trajetória de crescimento econômico de um país. Tentar-se-á construir uma ponte entre as escolas evolucionárias neo-schumpeteriana e neo-institucionalista, atrelando a mudança tecnológica à mudança institucional e, desta forma, compreender a forma como as trajetórias de crescimento econômico são definidas historicamente.

Palavras-chave: Inovações tecnológicas; Instituições; Crescimento Econômico.

Área 5: Mudanças técnicas, organizações e instituições

Classificação JEL: B25, E11, 033.

Abstract: The main purpose of this article is to approximate theoretical scope of two schools of economic thought, trying to demonstrate the narrow relation between technical change and institutional change and how the interaction between them determines the economic growth path of a country. It will try to build a bridge between neo-schumpeterian and neo-institutionalist evolutionary schools, coupling up technological change to institutional change and, in this way, understanding how economic growth paths are historically defined.

Key-words: Technological Innovation; Institutions; Economic Growth.

Section 5: Technical chamge, organizations and institutions

JEL Classification: B25, E11, 033.

\footnotetext{
${ }^{1}$ Aluno do curso de doutorado do Programa de Pós-Graduação em Economia da UFRGS (PPGE/UFRGS). Bolsista Capes. Professor do departamento de Economia da Universidade de Santa Cruz do Sul (Unisc). Email: castellijonattan@gmail.com

2 Doutor em Economia pela Universidade Federal do Rio Grande do Sul (UFRGS). Professor Associado da Universidade Federal do Rio Grande do Sul (UFRGS). E-mail: octavio@ufrgs.br
} 


\section{INTRODUÇÃO}

O sistema capitalista é caracterizado por situações de desequilíbrios e descontinuidades com a situação presente, ocasionadas, muitas vezes, pela introdução de inovações que alteram o seu modus operandi (SCHUMPETER,1982). Neste sentido, uma teoria econômica baseada na mudança técnica deve ser uma teoria do desequilíbrio e de um processo cumulativo e evolucionário da mudança dos meios de produção. Sendo o mercado, de acordo com Nelson (2006), não um ambiente de alocação e trocas perfeitas de recursos e mercadorias em concorrência perfeita, mas sim um local em que ocorre variedade e seleção, aproximando-se mais de um enfoque analítico análogo à teoria evolucionária darwiniana, da biologia, do que com a mecânica e o equilíbrio da física.

A análise estática, conforme Schumpeter (1982), não só é completamente incapaz de predizer as consequências de mudanças arbitrárias na forma tradicional de se produzir as coisas, como sequer consegue explicar a ocorrência das revoluções produtivas, decorrente do processo inovativo, e os fenômenos que as acompanham. Ela só pode investigar a nova posição de equilíbrio após as mudanças já terem ocorrido ${ }^{3}$. De tal forma que o autor austríaco frisa que "a questão não é como o sistema administra ditas estruturas, mas como ele as cria e as destrói” (SCHUMPETER, 1984; p.112).

Uma teoria evolucionária, por conseguinte, é aquela que possui uma clara conotação de se preocupar com "processos de mudança de longo prazo e progressivos" (NELSON; WINTER, 2005; p. 26). Ou seja, ela é path-dependent, dando maior ênfase ao processo de transformação das estruturas econômicas e sociais do que ao equilíbrio. É a mudança o cerne desse tipo de abordagem, sendo as escolas neo-schumpeteriana e institucionalista aquelas que carregam em seu corpo teórico os elementos análogos à biologia evolucionista. Cada uma delas possui seu próprio elemento-chave da mudança econômica e social, que funciona como uma espécie de genes que carregam em seu código as características que se confrontarão no processo de seleção evolucionária. Na teoria neoschumpeteriana esse elemento-chave é a mudança técnica e as rotinas das firmas, enquanto na escola institucionalista esses genes são as instituições e os hábitos dos indivíduos.

Os principais elementos que são emprestados do evolucionismo darwiniano para a escola neo-schumpeteriana são os conceitos de seleção, adaptação e herança. A seleção aparece no sentido de indicar que, como já assinalado acima, o mercado é um locus de seleção, que determinará quais tecnologias, produtos e empresas sobreviverão e quais não. Através de uma concorrência feroz, longe da concorrência perfeita, que se dá mais pela diferenciação qualitativa das mercadorias do que por uma guerra de preços. A adaptação sugere que à medida que as condições de concorrência se alteram e são introduzidas inovações, como artigos de maior valor agregado e novos processos que reduzem os custos de produção, os agentes econômicos, se quiserem sobreviver, se adaptam a essas novas condições, passando a adotar as inovações difundidas no mercado. E a herança revela o

\footnotetext{
${ }^{3}$ Nelson e Winter (2005), porém, previnem que: “Associar a ortodoxia à análise do equilíbrio estático é uma caricatura, mas salientar que a contínua confiança na análise do equilíbrio, mesmo em suas formas mais flexíveis, ainda deixa a disciplina bastante cega aos fenômenos associados à mudança histórica não é uma caricatura. (...) Portanto, embora não seja literalmente apropriado estigmatizar a ortodoxia como estando preocupada apenas com situações hipotéticas de perfeita informação e equilíbrio estático, a prevalência de restrições análogas no trabalho avançado confere uma validade metafórica à alegação” (NELSON; WINTER, 2005; p. 24).
} 
caráter cumulativo desse processo de mudança econômica. Apesar da incorporação desses elementos darwinianos, cabe ressalvar que:

\begin{abstract}
"Os processos através dos quais as tecnologias evoluem são também diferentes em importantes aspectos do processo evolucionário na biologia. Em particular, a proposição de que a tecnologia evolui no sentido evolucionário não nega ou diminui o papel da intenção humana no processo, ou o poderoso corpo de conhecimentos e técnicas às vezes utilizado para guiar os esforços daqueles que buscam o avanço tecnológico. Assim, esforços de invenção e inovação não significam serem totalmente cegos, ou estritamente randômicos, como frequentemente é assumido como sendo um caso que lembra a mutação biológica. Ao mesmo tempo, o propósito de busca não implica qualquer correspondência entre os resultados previstos e os realizados” (DOSI; NELSON, 2010, p.65, tradução nossa).
\end{abstract}

Na teoria institucionalista, por sua vez, os elementos evolucionários emergem na forma da cumulatividade, do caráter não-teleológico do processo de evolução da economia e de suas instituições, do conceito de inércia - onde uma instituição pode perdurar mesmo não estando de acordo com as condições materiais de uma sociedade -, do conceito de instituições como unidades de seleção, entre outras concepções do evolucionismo darwiniano.

Diante disso, entendem-se as teorias neo-schumpeteriana e institucionalista como evolucionárias por terem em seu âmago os elementos assinalados acima. E se deixa claro a necessidade de uma análise evolucionária devido ao caráter dinâmico do capitalismo. Do mesmo modo, o Sistema Nacional de Inovação e a trajetória tecnológica e de crescimento de um país são condicionados pelo seu ambiente institucional. Desta forma, o objetivo deste artigo é fazer uma aproximação do escopo teórico dessas duas correntes do pensamento econômico, tentando demonstrar a estrita relação entre mudança técnica e mudança institucional e que a interação entre elas determina a trajetória de crescimento econômico de um país.

Isto posto, este artigo contará com cinco seções, incluindo esta introdução. $\mathrm{Na}$ segunda seção apresentar-se-á os principais elementos da teoria evolucionária neoschumpeteriana e a visão dessa escola sobre como se dá a mudança econômica. Já a terceira seção explicitará os principais elementos teóricos do neo-institucionalismo a respeito da forma como evoluem as estruturas socioeconômicas. Na quarta seção se tentará construir uma ponte entre as escolas evolucionárias neo-schumpeteriana e neoinstitucionalista, atrelando a mudança tecnológica à mudança institucional e, assim, compreender a forma como as trajetórias de crescimento econômico são definidas historicamente.

\title{
2. A ABORDAGEM EVOLUCIONÁRIA DA ESCOLA NEO-SCHUMPETERIANA
}

A concepção de o progresso técnico ser a força motriz do crescimento econômico e de esse avançar através de um processo evolucionário não é uma ideia nova. Essa percepção está presente na teoria econômica desde a Riqueza das Nações de Adam Smith, quando esse autor trata da especialização do trabalho dentro das fábricas inglesas. Na visão de Adam Smith o que explicaria, em grande medida, os ganhos de produtividade do trabalho seria a invenção de máquinas que facilitavam e encurtavam-no, permitindo um homem realizar o trabalho de muitos. Mais tarde, autores como Marx e Schumpeter relacionariam as mudanças sócio-econômicas com as transformações do modo de produção, a relação entre trabalhadores e capital fixo (a composição orgânica do capital), impulsionadas por novas tecnologias.

Por essa razão não é exagero afirmar que a história da própria civilização é inseparável da história do progresso técnico, se considerarmos que essa se constitui dos 
esforços da humanidade para aumentar a produtividade diante de um conjunto variado de condições ambientais (ROSENBERG, 2006). Portanto, para se atingir um maior entendimento a respeito do processo de crescimento das economias capitalistas é fundamental que se compreenda o processo de mudança técnica.

Apesar de ser quase uma unanimidade, algo raro nas ciências econômicas, a percepção de que o progresso técnico tem um papel central para o crescimento econômico, o estudo desse fenômeno encontra sérias dificuldades na própria definição do que ele é. E esse obstáculo surge da sua natureza "camaleônica". Ele não é uma coisa, mas várias simultaneamente. Talvez, a característica comum "a essa multiplicidade de formas seja o fato de o progresso técnico produzir (1) um maior volume de produto ou (2) um produto qualitativamente superior” (ROSENBERG, 2006; p.18). Entretanto, convém salientar, que a segunda categoria, "produzir um produto qualitativamente superior”, não é secundária, ao contrário. É a introdução de novos produtos que, em última instância, torna o sistema capitalista tão dinâmico. Logo, uma das falhas da análise da teoria econômica tradicional, no que tange ao progresso técnico, é considerá-lo como a mera introdução de novos processos produtivos que têm a capacidade de reduzir custos de produção, quando na verdade ele é muito mais do que isso.

Tal análise decorre do fato de que para a teoria tradicional a concorrência entre firmas se dá através, principalmente, via preços. Assim, a função última do progresso técnico seria reduzir os custos de produção para que as firmas possam concorrer nos preços. Porém, o processo de concorrência que importa para explicar a evolução do sistema capitalista como um todo não é o que se dá pelos preços, mas sim pela introdução de novos produtos, novas qualidades (SCHUMPETER, 1982). Nas palavras de Rosenberg (2006), "excluir do progresso técnico a inovação de produtos (...) equivale a encenar Hamlet sem o príncipe” (ROSENBERG, 2006; p.19).

Para Schumpeter (1982) o que explica o desenvolvimento econômico é o processo de inovação. Segundo ele, as inovações transformadoras não podem ser previstas ex-ante e a evolução econômica caracterizar-se-ia por rupturas e descontinuidades com a situação presente, através da introdução de novidades na maneira de o sistema capitalista funcionar. Uma inovação não é apenas uma nova tecnologia física, mas também pode ser uma nova forma de organizar a produção. Isto posto, Schumpeter (1982) define cinco tipos possíveis de inovação: i) a introdução de um novo bem, uma nova mercadoria, ou uma nova qualidade de um bem; ii) a introdução de um novo método de produção; iii) a abertura de um novo mercado; iv) a conquista ou descoberta de uma nova fonte de insumos, sejam novas matérias-primas ou bens semimanufaturados; v) e o estabelecimento de uma nova organização de indústria ou o fim de uma posição de monopólio.

Deve-se destacar o papel da ciência na introdução de inovações. Muitos dos produtos capazes de revolucionar o mercado foram, de alguma forma, gestados nos laboratórios de universidades. Entretanto, a relação entre ciência e inovação não é determinista. Não são os avanços científicos que determinarão quais produtos serão incorporados ao mercado. Na verdade, esta relação é muito mais interativa e dialética do que se pode supor. As firmas podem incorporar uma tecnologia criada para fins científicos, ou até militares, em seus produtos, como é o caso do GPS, por exemplo, que surgiu para uso militar. Assim como um avanço científico pode ser realizado no intuito de suprir uma necessidade de mercado. Por exemplo, o desenvolvimento da ciência da bacteriologia surgiu das tentativas de Pasteur em resolver os problemas de fermentação e putrefação encontrados na indústria vinícola francesa (ROSENBERG, 2006).

Além disso, o ponto crucial que se deve ressaltar é de que a análise da escola neoschumpeteriana está alicerçada em um distanciamento da concepção de equilíbrio neoclássico. As inovações alteram a partir de dentro os parâmetros do sistema econômico 
que, por ser evolucionário, não conhece o equilíbrio e, em razão disso, transcorre ao longo do tempo fazendo com que sua natureza seja histórica (path dependent). Assim, os autores neo-schumpeterianos, como Giovani Dosi, Richard Nelson, Chris Freeman e Carlota Perez, endogenizaram a mudança técnica, tanto a criação quanto a absorção de tecnologia. Opondo-se, claramente, à visão da teoria ortodoxa tradicional, na qual a tecnologia é uma variável exógena ao modelo de crescimento econômico.

Mesmo modelos ortodoxos de crescimento econômico que assimilam a ideia de Schumpeter de dar um papel fulcral à inovação tecnológica, como o modelo de Solow ou o ciclo real de negócios, não conseguem explicar como ela surge. Eles destacam a mudança tecnológica como uma variável fundamental para explicar o crescimento econômico, mas tratam tal processo transformador, simplesmente, como um 'choque tecnológico'.

A tecnologia, na teoria ortodoxa, é encarada como um maná que cai dos céus e não como uma variável chave que surge das próprias idiossincrasias do sistema capitalista. A firma neoclássica é uma grande caixa-preta, na qual se pressupõe seu caráter maximizador de lucro, porém não se busca discutir de que forma as firmas podem vir a ser o seio no qual nascem as inovações.

Esse tratamento às mudanças tecnológicas dada pelos autores neoclássicos sofreu muitas críticas por parte da heterodoxia, as quais assinalavam o quão limitada essa interpretação era, ao ignorar os retornos crescentes provenientes do conhecimento e, a partir disso, a existência de mercados imperfeitamente competitivos (COSTA, 2015). Isso causou certo desconforto mesmo no seio neoclássico, o que fez com que alguns autores dessa corrente se manifestassem a respeito.

De tal forma, na década de 1980, surgiram os modelos de crescimento endógeno, tentando explicar o progresso técnico como resultado do funcionamento natural do sistema de mercado. Por essa perspectiva os agentes econômicos se sentiriam impulsionados a investir na criação privada de novos conhecimentos, a fim de adquirir uma vantagem competitiva. Nesses modelos o conhecimento, embora permaneça sendo visto como um bem público, pertenceria a um tipo diferenciado. Romer (1990) assinala que o conhecimento seria um bem público especial, mantendo como propriedade a nãorivalidade, porém sendo parcialmente exclusivo, à medida que permitiria a produção de retornos a serem apropriados privadamente. Conforme Costa (2015), a premissa básica que sustentaria essa modelagem é a suposição de que o crescimento econômico seria guiado pela acumulação de conhecimento por agentes maximizadores, tendo, por fim, um modelo de crescimento de equilíbrio competitivo.

A despeito disso, mesmo esses modelos de crescimento endógeno mantêm em seu âmago os axiomas da teoria neoclássica, particularmente agentes racionais e otimizadores e o equilíbrio do sistema econômico. Dessa maneira, embora avancem em relação à teoria neoclássica tradicional, permanecem presos a algumas amarras dela e por isso não conseguem compreender a dinâmica da mudança técnica, essencialmente desequilibrista e permeada de incerteza. O que revela o quão incapaz a teoria ortodoxa ainda está para compreender o processo da mudança técnica.

Na teoria neo-schumpeteriana, em contrapartida, a natureza das tecnologias é mais complexa e heterogênea. Nas palavras de Dosi e Nelson (2010, p. 56, tradução nossa):

Nos termos mais gerais, uma tecnologia pode ser vista como meios projetados por humanos para se atingir um determinado fim - sendo desde um procedimento para se fazer aço, um equipamento para processar informação, como o computador, ou o conjunto de operações envolvidas em uma cirurgia cardíaca. Isso significa muito frequentemente implicar peças particulares de conhecimento, procedimentos e artefatos. Esses diferentes aspectos oferecem diferentes, porém complementares, formas de se descrever as tecnologias. 
Complementarmente, a origem dessas tecnologias acaba por assumir um caráter mais endógeno, não só ao sistema econômico, como às empresas que dele fazem parte. Assim sendo, se mantém um dos pontos fundamentais da análise de Schumpeter (1982) de que o processo inovativo não é um mero reflexo das novas necessidades que surgem do lado da demanda, mas um processo que se dá, principalmente, pelo lado da oferta:

\begin{abstract}
As inovações no sistema econômico não aparecem, via de regra, de tal maneira que primeiramente as novas necessidades surgem espontaneamente nos consumidores e então o aparato produtivo se modifica sob sua pressão. Não negamos a presença desse nexo. Entretanto, é o produtor que, igualmente, inicia a mudança econômica, e os consumidores são educados por ele, se necessário; são, por assim dizer, ensinados a querer coisas novas, ou coisas que diferem em um aspecto ou outro daquelas que tinham o hábito de usar. Portanto, apesar de ser permissível, e até mesmo necessário, considerar as necessidades dos consumidores como uma força independente e, de fato, fundamental na teoria do fluxo circular, devemos tomar uma atitude diferente quando analisamos a mudança. (SCHUMPETER, 1982; p. 48).
\end{abstract}

Essa postura de Schumpeter (1982) de compreender a origem do processo de inovação no lado da oferta teve continuidade nos trabalhos dos autores neoschumpeterianos, os quais buscaram explicar como as inovações surgiriam no âmbito da firma. Esses autores abrem a 'caixa-preta', a firma neoclássica, e revelam os meios pelos quais se dá a introdução de inovações no sistema capitalista.

\title{
2.1. Abrindo a 'caixa-preta': microfudamentos de uma teoria evolucionária neo- schumpeteriana
}

A teoria tradicional apresenta em seu cerne um conjunto de pressupostos básicos que são basilares para todas as explanações derivadas de seu arcabouço teórico. Esses pressupostos não são hipóteses falseáveis. Na verdade, são verdadeiros axiomas que engendram todo instrumental analítico dessa teoria. Tais pressupostos são: i) de que os agentes econômicos possuem racionalidade substantiva; ii) de que tanto os indivíduos quanto as firmas são maximizadores de utilidade. E mesmo quando não maximizam sua utilidade agem como se (as if) assim o fizessem; iii) a teoria tem como pilar estrutural o conceito de equilíbrio. Deste modo, a análise da teoria neoclássica caracterizar-se-ia por ser estática, preocupada em encontrar pontos de equilíbrio, como na tesoura marshaliana de oferta e demanda; iv) os agentes econômicos agem atomisticamente; v) os bens disponíveis no mercado são homogêneos, se diferenciando apenas nos preços; vi) e o mercado é a principal instituição na alocação de recursos, via mecanismo de preços. Bem dizer que, na teoria neoclássica, o mercado emerge quase como se fosse um quinto elemento da natureza (HODGSON, 1999; p. 109).

Por considerar os agentes econômicos e as mercadorias como homogêneos, a abordagem neoclássica acaba por não conseguir explicar como ocorre o surgimento das inovações. Nela a firma se defronta com uma função de produção e escolhe as técnicas que irá usar com base nos preços prevalecentes dos fatores de produção. Por conseguinte, as mudanças no espectro de técnicas disponíveis são consideradas exógenas.

Desta maneira, as limitações dessa escola do pensamento econômico na forma de tratar a mudança técnica das firmas manifestam-se por: i) incorporar somente os fatores capital e trabalho na função de produção; ii) pela suposição de existir um conjunto infinito de técnicas a um dado nível de tecnologia ser irrealista; iii) por a substituição entre capital e trabalho ser limitada; iv) por a função de produção descrever apenas as mudanças em tecnologias de processos e não captar as mudanças nos produtos; v) e por a função de 
produção só conseguir revelar as melhorias em termos de redução de custos. As melhorias no desempenho do produto, por exemplo, não são contempladas na função de produção.

Não obstante, a teoria evolucionária neo-schumpeteriana busca se afastar dos pressupostos supracitados. Na abordagem dos autores neo-schumpeterianos ao invés de racionalidade substantiva, escolha racional e agentes maximizadores tem-se a racionalidade limitada de Herbet Simon (1986). No lugar de uma análise estática e de equilíbrio, opta-se por uma análise dinâmica, evolucionária e path-dependent. Em substituição à ideia de concorrência pela diferenciação de preços dá-se ênfase à concorrência pela diferenciação qualitativa de produtos. Em oposição à atomicidade dos agentes econômicos, a interação entre esses agentes passa a ser um elemento importante na explicação do desempenho econômico. Sendo possível, inclusive, a transmissão de conhecimento e técnicas entre as diversas firmas e indivíduos à medida que esses interagem entre si. E em contraste a uma concepção de mercado como um ambiente de alocação perfeita de recursos surge um mercado como locus de seleção e variedade.

$\mathrm{Na}$ teoria neo-schumpeteriana a introdução de inovações ocorre de maneira sistêmica, ela não é um resultado meramente individual, mas decorre do ambiente institucional e econômico (Estado, produtores e consumidores) que as empresas estão inseridas. Por esse prisma tanto a oferta quanto a demanda desempenham um papel fundamental no processo de criação de novas mercadorias e modos de produção e na seleção desses (DOSI; NELSON, 2010).

Todavia, devido à clara orientação dos esforços teóricos dos autores neoschumpeterianos em alcançar um maior aprofundamento quanto à sua concepção de firma/empresa e de seu comportamento, a teoria acaba por se concentrar muito mais nos elementos intra-firma como forma de se explicar a introdução de inovações no sistema capitalista. Assim, o primeiro aspecto que transparece é de que a inovação não surge, necessariamente, pela mera adoção de avanços tecnológicos feitos com objetivos científicos, mas como uma forma de solucionar problemas internos das próprias firmas.

Outra questão é que a tecnologia não só não é exógena como também não está disponível no mercado para o uso de todas as empresas. Conforme Nelson (2006), na formulação neoclássica original, as novas tecnologias se difundem de maneira quase instantânea. Contudo, a tecnologia não é um bem-público. Ela pode pertencer a uma empresa específica e estar sujeita a medidas de proteção através de leis de patentes, por exemplo, o que dificulta sua difusão. Ademais, a questão essencial é que muitas vezes o conhecimento que está por trás da tecnologia desenvolvida não é codificável, possuindo um caráter muito mais tácito. Por conseguinte, Nelson (2006) assinala que existem dois mecanismos principais de difusão de uma tecnologia lucrativa: a difusão de firma para firma e pelo crescimento das empresas que utilizam a tecnologia superior em relação às que não o fazem.

Claro que, com o tempo, as outras empresas poderão copiar essa tecnologia que era restrita a uma única empresa. No entanto, ninguém garante que as cópias serão tão boas quanto o original. Além disso, é bem provável que quando a tecnologia estiver totalmente difundida outra já terá surgido em substituição. E como bem evidenciou Nelson (2006) "a tecnologia de amanhã frequentemente nasce das experiências de criar e de usar a de hoje" (NELSON, 2006; p. 109). Mais do que isso, Dosi e Nelson (2010) arguem que a geração de conhecimento tecnológico e informação pura envolvem um alto custo, se comparado ao da sua repetida utilização. Consequentemente, há uma propriedade fundamental de retornos crescentes para o uso de informação e conhecimento tecnológico. Por essa razão uma empresa que possua uma vantagem de conhecimento em um nicho particular da tecnologia atual tenderá a manter uma vantagem amanhã na mesma tecnologia ou em tecnologias adjacentes. 
Isso traz à tona mais um elemento fundamental da teoria neo-schumpeteriana que é o entendimento de que as empresas se diferem entre si. Elas não são iguais, homogêneas, como aventa a teoria neoclássica. Elas possuem características distintas, formas de organizar a produção e conhecimentos diferentes. Nelson (2006) assevera que essa tendência de os economistas ignorarem as diferenças entre as firmas reside no interesse deles em analisar, não as empresas individualmente, mas agregados mais amplos, como um ramo específico ou a economia como um todo. Com isso se perde uma célula de análise de grande relevância para o estudo da mudança técnica.

O conhecimento é uma variável que interfere diretamente na capacidade de as firmas inovarem. Se for lógico que as firmas e os indivíduos possuem graus de conhecimento distintos, também seria lógico considerar que as firmas têm capacidades inovativas distintas. Cohen e Levhintal (1990) desenvolveram o conceito de capacidade absortiva para representar a habilidade das firmas de assimilar novas tecnologias e informações em seus processos inovativos. Essa habilidade representa a capacidade das firmas tanto em reconhecer o valor do "novo" como de aplicá-lo a fins comerciais. Segundo os autores a capacidade absortiva e, consequentemente, a performance inovativa das firmas é path-dependent, onde a falta de investimentos em uma área de especialização, de conhecimento, pode entravar o futuro desenvolvimento técnico da firma nessa área.

A absorção de conhecimento externo à firma é crucial para o processo inovativo. De fato, muitas inovações resultam mais do ato de "pegar emprestado" informação externa do que da invenção propriamente dita. Desta maneira, a habilidade de explorar conhecimento externo é um componente fundamental das capacitações inovativas de uma firma. Nas firmas a capacidade absortiva aparece, muitas vezes, incorporada em suas rotinas de produção.

A rotina pode ser compreendida como um repositório de conhecimento. O conceito de rotina admite escolha dentro de um grupo limitado de alternativas. Ela conserva as características produtivas e inovativas das firmas, se apresentando como um dos principais fatores que diferenciam as empresas entre si. As rotinas são os genes das firmas, são características hereditárias difíceis de copiar. O crescimento econômico é causado pelas mudanças na distribuição das operações rotineiras associadas tanto à criação de novas rotinas superiores, e a adoção em larga escala dessas, quanto ao abandono das inferiores.

Uma rotina envolve uma coleção de procedimentos que tomados conjuntamente resultam em um produto previsível e específico, sendo que "rotinas complexas" podem ser, quase sempre, divididas em sub-rotinas. Um aspecto chave das rotinas produtivas que deve ser destacado é que, em geral, elas, desconsiderando pequenas vicissitudes, se assemelham às rotinas adotadas por outras organizações em um contexto semelhante. Há duas razões para que uma rotina produtiva seja amplamente adotada. A primeira é que ela tende a ser o resultado de contribuições acumulativas de muitas partes, às vezes até de muitas gerações. E a segunda razão é de que rotinas particulares tendem a ser uma parte de um sistema de rotinas.

Convém salientar que as rotinas de uma firma surgem, inicialmente, como uma forma de otimizar o processo produtivo, de reduzir custos e tempo necessário para a produção das mercadorias. Deste modo, a rotina se apresenta como uma verdadeira heurística de uma firma. Entretanto, elas podem não ter, necessariamente, um caráter de otimização do processo produtivo, podendo, inclusive, ser um entrave a ele. A rotina, assim, emerge quase como um hábito da firma, sendo difícil alterá-la.

As firmas buscam a "melhor rotina" para adotar em seu processo produtivo. Contudo, a adoção dessa melhor prática dependerá da capacidade absortiva das firmas, das habilidades de seus funcionários e de suas próprias idiossincrasias. É muito complicado 
copiar uma rotina, pois ela nasce em um contexto específico e tentar reproduzi-la em uma situação distinta pode resultar em um produto adverso (NELSON; WINTER, 2005).

Uma questão fundamental que convém indagar é: qual é a relação entre as rotinas e o irrompimento de inovações no âmbito das firmas?

O primeiro aspecto é que as operações rotineiras de uma organização contribuem para o surgimento de inovações através de enigmas e anomalias relacionados às rotinas vigentes (NELSON; WINTER, 2005). Desta forma, os esforços para solucionar os problemas e dificuldades enfrentados por uma rotina existente podem levar a inovações. Além disso, a inovação das rotinas de uma firma consiste na combinação de rotinas já existentes na busca para a solução de um novo obstáculo. Esta nova combinação pode envolver, por exemplo, simplesmente um novo padrão de transmissão de informação dentro da firma ou até a substituição de uma sub-rotina por outra considerada melhor. Destarte, a evolução das rotinas de uma firma pode resultar em um novo modo de se produzir as coisas, ou até em um novo tipo de mercadoria, conduzindo, assim, à emergência de uma inovação.

\subsection{Paradigmas e trajetórias tecnológicas}

A despeito de ser característica do sistema capitalista a permanente introdução de inovações no seu modo de produção, somente algumas poucas dessas conseguem se difundir tão amplamente a ponto de serem capazes de alterar a forma como se produzem as mercadorias ao redor do globo. Dosi (1982) introduz o conceito de paradigma tecnológico para denominar aquelas tecnologias capazes de transformar não só todas as mercadorias e a forma de produzi-las como a maneira que as pessoas vivem suas vidas.

Um "paradigma tecnológico" define contextualmente as necessidades que são importantes de serem preenchidas; os princípios científicos utilizados nas tarefas e o material tecnológico a ser usado. Em outras palavras, um paradigma tecnológico pode ser definido como um 'padrão' de solução de problemas econômicos selecionados, baseados em princípios derivados das ciências. Os paradigmas tecnológicos, portanto, definem as oportunidades tecnológicas das inovações. Tal noção se baseia em uma concepção de tecnologia sustentada por três ideias fundamentais: i) a "tecnologia" não se restringe apenas a um conjunto de projetos bem definidos, mas também às atividades solucionadoras de problemas, que envolvem as formas tácitas de conhecimento existentes nos procedimentos individuais e organizacionais; ii) os paradigmas englobam uma heurística própria e formas específicas de “como fazer as coisas” e como melhorá-las, compartilhadas entre os profissionais das mais diversas atividades econômicas, se apresentando como um marco de cognição coletiva; iii) e os paradigmas definem os modelos básicos dos produtos industriais e os sistemas de produção (CIMOLI; DOSI, 1994).

Isto posto, o paradigma tecnológico se apresenta como a "melhor prática", a melhor forma de se produzir as coisas, e é incorporado em praticamente todos produtos possíveis. Porém, ao contrário do que se pode pensar, o paradigma tecnológico pode não ser a tecnologia mais avançada existente. Arthur (1989) salienta que às vezes uma tecnologia inferior vem a se tornar o paradigma tecnológico por razões que não são relacionadas a seu desempenho. Uma tecnologia inferior pode se difundir a ponto de se tornar um paradigma devido a questões políticas, de hábitos dos indivíduos, de custos para a aquisição e incorporação dessa tecnologia (como gastos elevados em treinamento) etc., isto é, devido ao que Brian Arthur denomina de "pequenos eventos”, e lock-in a indústria em uma tecnologia inferior, sendo muito difícil reverter tal situação.

À medida que um paradigma se difunde ele cria uma trajetória, associada com o desenvolvimento progressivo das oportunidades de inovação relacionadas a ele, e que determinarão a forma como as economias se transformarão ao longo dos anos. Conforme 
Cimoli e Dosi (1994), a princípio, as trajetórias podem ser medidas com base nas mudanças nas características tecno-econômicas fundamentais dos produtos e do processo de produção. As principais características de uma trajetória tecnológica são: i) cada corpo específico de conhecimento (por exemplo, cada paradigma) dá forma e restringe o ritmo e a direção da mudança tecnológica, independentemente dos estímulos de mercado; ii) em consequência, observasse regularidades no padrão da mudança técnica em diversas condições de mercado (por exemplo, para distintos preços relativos) cuja interrupção se relaciona com mudanças radicais nas bases do conhecimento (paradigmas); iii) a mudança técnica se deriva em parte das tentativas de enfrentar os desequilíbrios tecnológicos que tal mudança provoca.

A trajetória definida pelo surgimento e difusão de um paradigma tecnológico tem como consequência criar o gérmen do qual brotará o próximo paradigma. Esse aspecto evolutivo se assenta na cumulatividade dos sucessos inovativos de cada paradigma e os fazem se distinguir entre si. De tal forma que, embora um paradigma tecnológico possa ter sido impulsionado pelos desenvolvimentos tecnológicos do anteriores, ele não é uma mera extensão desse, mas sim uma ruptura revolucionária. Dosi e Nelson (2010) asseveram que essa cumulatividade capta a natureza incremental da busca tecnológica, e, crucialmente, varia muito ao longo de diferentes atividades inovadoras. Apesar disso, esses dois autores destacam que a cumulatividade do processo inovativo pode ser compreendida em termos de probabilidades futuras de sucesso condicionado por realizações passadas de um processo estocástico. Como resultado ter-se-ia uma dinâmica de retornos crescentes baseada em conhecimento.

Portanto, uma inovação ao se tornar um paradigma tecnológico segue uma trajetória de difusão entre firmas e países e de surgimento de pequenas inovações complementares a ela. Ao fim dessa trajetória, na qual o paradigma tecnológico está altamente difundido e é utilizado nos mais diversos aspectos da produção capitalista e da maneira como os indivíduos vivem suas vidas, a tecnologia que outrora foi uma grande inovação chega ao seu limite, dando margem ao surgimento de uma nova inovação tecnológica e, por conseguinte, dando espaço para a aurora de um novo paradigma tecnológico.

\section{A ABORDAGEM EVOLUCIONÁRIA DA ESCOLA NEO-INSTITUCIONALISTA}

Enquanto a escola evolucionária neo-schumpeteriana tem como elemento-chave da evolução da economia o progresso técnico, as instituições emergem como célula de análise e principal móvel da mudança sócio-econômica na abordagem da tradição institucionalista. De maneira a Thorstein Veblen ter afirmado que "a evolução da estrutura social foi um processo de seleção natural das instituições” (VEBLEN, 1965; p.177).

A abordagem neo-institucionalista descende e é fortemente influenciada tanto por Thorstein Veblen e pelo Antigo Institucionalismo quanto pela crescente força da teoria neo-schumpeteriana. Essa vertente do pensamento institucionalista retoma os ensinamentos de Veblen, Commons e Mitchell e endogeiniza os indivíduos, suas preferências e seus hábitos (CONCEIÇÃO, 2002).

Consoante Hodgson (1994) o “corpo do conhecimento" do Neo-institucionalismo ${ }^{4}$ é composto de oito atributos principais: i) a rejeição do atomismo e do reducionismo na

\footnotetext{
${ }^{4}$ Saliente-se que para a tradição do Antigo Institucionalismo, o termo "neo-institucionalismo" não é passível de aceitação, havendo claro desconforto da inclusão de seus próprios nomes na referida nomenclatura. Para eles, o institucionalismo tem hoje duas versões: o velho (ou original institutional economics) e o novo (da New Institutional Economics). Vide a este respeito Samuels (1995), Rutherford (1999) e Stanfield (1999). Como salientado, preferimos seguir a dicotomia sugerida por Samuels, designando de "neoinstitucionalistas” os seguidores contemporâneos de Veblen, Commons e Mitchell e críticos à NEI.
} 
análise econômica, optando por alternativas holísticas ou organicistas; ii) em substituição ao homo economicus neoclássico, agente racional e maximizador, surge o homo institutionalis, guiado por seus hábitos e rotinas e que, de vez em quando, se guia por um ímpeto criativo e introduz novidades; iii) no lugar do individualismo metodológico, as instituições são a principal célula de análise; iv) ao invés da análise estática e equilibrista neoclássica, se adota a concepção de um sistema econômico path-dependent, de causação cumulativa, onde a história tem um peso muito grande; v) as preferências dos agentes econômicos não são dadas, nem fixas, mas sim moldadas e condicionadas pela estrutura social e cultural na qual os indivíduos se inserem; vi) ao contrário do apregoado pelos modelos neoclássicos, a tecnologia não é exógena, mas sim endógena, sendo a força motriz do desenvolvimento sócio-econômico e evoluindo ao longo da passagem do tempo; vii) enquanto a teoria tradicional e a NEI desconsideram as relações de poder em seu corpo analítico, o Neo-institucionalismo se interessa tanto por essas relações como pelos conflitos entre os indivíduos e instituições, se aproximando, neste sentido, da sociologia e de autores como Max Weber; viii) e se afasta das teorias utilitaristas, na avaliação do bemestar social a partir da utilidade individual, se focando na identificação das necessidades reais humanas e do arranjo institucional que pode auxiliar na sua identificação e clarificação (HODGSON, 1994; p.69).

Hodgson (2006) define as instituições como sendo um "sistema de regras sociais estabelecidas e prevalecentes que estruturam as interações sociais” (HODGSON, 2006; p.2), como, por exemplo, as leis, a moeda, o sistema de peso e medidas, a linguagem e as firmas. Mais do que isso, no Neo-institucionalismo as instituições e os indivíduos se confundem. As instituições nascem da interação entre os indivíduos, mas também moldam essa interação e a forma como os agentes econômicos se comportam. Isto é, "as instituições moldam e são moldadas pela interação humana, elas são tanto ideias subjetivas na cabeça dos agentes quanto estruturas objetivas encaradas por eles” (HODGSON, 1998; p.181, tradução nossa).

De maneira que Hodgson (1998) vai além e afirma que as instituições não só restringem e influenciam os indivíduos, como na abordagem dos autores filiados a NEI, mas, juntamente com o ambiente natural e a herança biológica, os seres sociais são constituídos de instituições, elas são “dadas pela história e constituem nossa carne e sangue socioeconômicos” (HODGSON, 1998; p.189).

A matéria que constitui as instituições, por outro lado, são os hábitos. Os hábitos dos indivíduos reforçam e são reforçados pelas instituições sociais. Entretanto, Hodgson (2006) ressalta que os hábitos são adquiridos no contexto social e não pela transmissão genética hereditária. Eles se derivam de comportamentos repetidos dos indivíduos. A origem dos hábitos de um indivíduo pode residir tanto em uma disposição inata ou mesmo na tendência a se imitar o comportamento dos outros agentes em um contexto social específico. Destarte, o hábito é em sua essência um resultado da interação social.

O processo de transformação institucional das estruturas socioeconômicas se principia, como aventado por Veblen (1965), na mudança dos hábitos de pensamento e ação dos agentes econômicos que se adaptam às novas condições ambientais e materiais de uma sociedade. A transformação do arranjo institucional aparece nos escritos de Veblen a partir de sua análise da causação cumulativa, ou seja, uma ação, mudança, passada estabelece uma nova situação que sofrerá, com o passar do tempo, novas alterações levando a uma nova situação, de maneira que sempre o fantasma do passado se manifesta no presente.

No princípio há um conjunto de instintos dados e um estilo de vida definido, com hábitos de pensamento e instituições estabelecidas. Com o tempo o arranjo institucional pode mudar como resposta a uma alteração na forma como os indivíduos interagem, nas 
suas atividades econômicas e sociais, mas, principalmente, por alguma alteração nas bases materiais da sociedade, o surgimento de novas tecnologias em particular. Os indivíduos se adaptarão às novas condições materiais, mudando seu estilo de vida e hábitos de pensamento e de ação.

À medida que os novos hábitos tomarem o lugar dos antigos se constituirá novas instituições que substituirão àquelas que forem incompatíveis com a nova realidade, assistindo, assim, a alvorada de uma nova estrutura institucional. Desta maneira, a mudança institucional ocorre através do desuso e substituição de antigos por novos hábitos, promovidos pelo novo ambiente material.

Ao contrário do que supõe a NEI, de que a evolução institucional das estruturas sociais e econômicas seja um processo que se dê de cima para baixo, isto é, primeiro mudam as "regras do jogo" e então os agentes se adaptam a elas, Hodgson (2006) salienta que, na realidade, é o inverso. Primeiro as crenças dos indivíduos se alteram, decorrente de uma mudança na base material da sociedade, e após essas se tornam hábitos e esses são convencionados como instituições.

Figura 1 - Reconstitutive Downard Causation

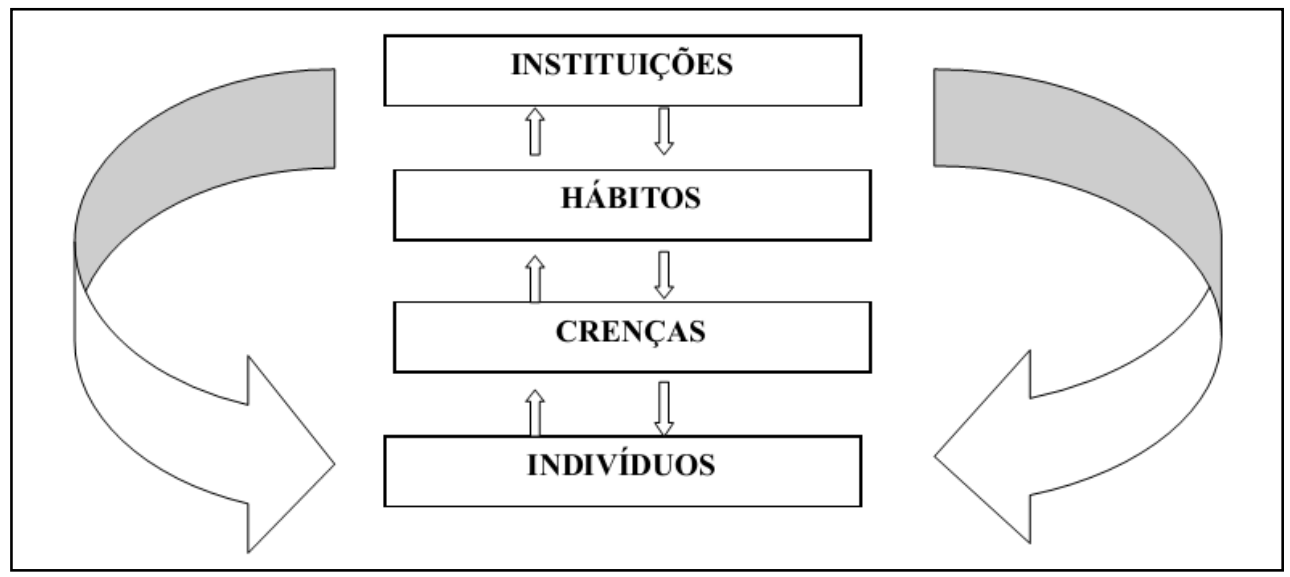

Fonte: Elaboração própria, a partir de Hodgson (2006).

Todavia, as novas instituições podem alterar as crenças e hábitos dos indivíduos, delimitando um processo de causação circular da transformação do arranjo institucional, denominado por Hodgson (2006) como Reconstitutive Downard Causation, que pode ser observado na figura acima. As setas apontadas para cima representam os estímulos geradores do nível superior e as setas apontadas para baixo, assim como as duas grandes setas laterais, representam o feedback de cada nível superior para o inferior.

Isto posto, o objeto de estudo da escola neo-institucionalista é compreender como o processo acima ocorre. De que maneira os indivíduos adquirem seus hábitos e como esses são convencionados como instituições. Mais precisamente, o grande problema que, segundo Hodgson (1998) se apresenta como cerne da agenda de pesquisa da Economia Institucional é precisar como as instituições moldam os hábitos e crenças dos indivíduos e como isso se reflete no desenvolvimento sócio-econômico das nações.

Uma conclusão pertinente a esse tipo de análise, com os hábitos exercendo uma função primordial na constituição das instituições, é de que uma lei, regra, convenção ou mesmo uma política econômica só consegue se institucionalizar à medida que esteja assentada nos hábitos de pensamento e comportamento dos agentes econômicos. Por conseguinte, quando se analisa o desenvolvimento econômico das nações e a divergência existente entre elas, o processo de reversão do atraso não se passa magicamente pela mera 
adoção de "boas instituições" como propõem os autores da NEI. Estratégias de mera emulação das instituições dos países centrais pelos países em desenvolvimento não encontram respaldo sob a ótica neo-institucionalista.

A construção do arranjo institucional de um país é realizada historicamente, através da interação dos agentes econômicos e pela seleção daquelas instituições que melhor se adaptam a uma realidade material - embora instituições arcaicas possam permanecer na estrutura sócio-econômica - e não pela cópia de modelos estrangeiros. O ato de emular uma lei, regra ou política que, no entanto, não encontre aderência nos hábitos de pensamento dos agentes econômicos está fadada ao fracasso e a não se institucionalizar.

\section{CONSTRUINDO UMA "PONTE”: UMA APROXIMAÇÃO DAS TEORIAS EVOLUCIONÁRIAS NEO-SCHUMPETERIANA E INSTITUCIONALISTA}

É importante frisar que se, por um lado, o crescimento econômico tem como força motriz a revolução de suas forças produtivas e a introdução permanente de inovações, como afirmado por Schumpeter (1984) e reiterado pelos autores neo-schumpeterianos, por outro lado, existe uma dimensão institucional desse processo assinalada pela escola institucionalista. Mais do que isso, a transformação do sistema capitalista se dá pela coevolução das estruturas físicas e sociais, isto é, das máquinas e técnicas de produção e das instituições de certa sociedade. Em razão disso, Nelson (2002) salienta que para se ter um maior entendimento da dinâmica do processo de mudança econômica deve ser construída uma "ponte" ligando a teoria econômica evolucionária, neo-schumpeteriana, à escola neoinstitucionalista. Ou seja, se deve atrelar o processo de mudança técnica ao processo de mudança institucional.

Consoante esse autor, há muitas afinidades entre a teoria institucional e a neoschumpeteriana: i) as duas escolas compartilham a premissa central de que as ações e interações humanas devem ser entendidas como o compartilhamento de hábitos e pensamentos; ii) ambas rejeitam profundamente o conceito de maximização como característica dos atores humanos e também rejeitam a ideia de Friedman de que o comportamento pode ser previsto por uma análise que calcule o melhor comportamento humano possível em um dado contexto. Isto é, se os agentes não podem maximizar eles agem "como se" assim o fizessem; iii) e essas escolas possuem o interesse em entender os determinantes da performance econômica e como ela se difere entre diferentes países e ao longo do tempo.

Zysman (1994) ressalta que as trajetórias de crescimento são criadas historicamente, partindo da trajetória de desenvolvimento das instituições nacionais que, muitas vezes, já estão enraizadas na estrutura sócio-econômica. Destarte, a história importa, o desenvolvimento das nações distinguir-se-ia por estar assentado em um conjunto de instituições distintas, como apontado por North (1990), mas que, ao contrário do afirmado pelos autores da NEI, não podem ser escolhidas racionalmente, não é um mero regramento, mas estruturas sociais que têm origem nos hábitos dos indivíduos e que, por isso, são difíceis de serem alteradas. Segundo Zysman (1994), as diferentes condições históricas e institucionais desenham os sistemas nacionais de inovação e as trajetórias tecnológicas de um país. Portanto, não é possível compreender as mudanças técnicas e institucionais de maneira desvinculada.

Ainda, conforme Metcalfe (2001), são as instituições que dão forma ao crescimento do conhecimento científico, tecnológico e social. Para esse autor, "o capitalismo é incansável, pois o conhecimento é incansável” (METCALFE, 2001; p.9). Desta forma, as instituições são basilares para o crescimento econômico e para o processo inovativo por duas razões principais. A primeira é que as instituições constituem os meios de armazenamento e comunicação de informações e os meios que dão suporte a padrões de 
interação particulares (diferentes padrões de interconexão implicam diferentes padrões de entendimento e diferentes caminhos para o crescimento do conhecimento). E segundo, pelas instituições serem as "regras do jogo", o padrão de comportamento socialmente acordado, que são os meios de se acumular conhecimento em relação à ciência e tecnologia.

Em consonância a isso, Nelson (2008) aponta que o crescimento econômico envolve tanto a evolução das tecnologias físicas (máquinas) quanto das sociais (rotinas, padrões de organização da produção, divisão do trabalho), no qual as instituições exercem um papel fundamental. As tecnologias sociais, na acepção de Nelson, podem ser vistas como modos de governança, muito próximas da noção de instituições de Williamson (2000), servindo como redutoras dos custos de transação. O conceito de tecnologias sociais englobaria tanto as formas de organizar as atividades dentro de uma firma como também as formas de transação entre as organizações.

Contudo, as instituições não são apenas um entrave ao avanço material das sociedades. Elas são também agentes de mudança na medida em que moldam o conhecimento e sua aplicação à resolução de problemas. Portanto, as instituições podem vir a gerar condições favoráveis aos avanços tecnológicos e à continuidade do crescimento econômico. Para Nelson (2008), as instituições são entendidas como estruturas e forças que moldam e sustentam as tecnologias sociais.

A estreita relação entre o institucionalismo e o evolucionismo também é destacada por Hodgson (1998). Esse autor assevera que a ênfase institucionalista no hábito e nas rotinas se encaixa bem com os modelos evolucionários desenvolvidos por Nelson e Winter (2005) e seus seguidores. Há uma proximidade entre o conceito de hábitos de pensamento e ação veblenianos e as rotinas produtivas das firmas neo-schumpeterianas. À medida que os dois representam uma espécie de repositório de conhecimento e por serem constituídos de uma natureza ambígua que provém tanto as bases para a "continuidade como para a mudança, tanto para a inércia quanto para a novidade” (HODGSON, 1998; p.175, tradução nossa).

As rotinas e os hábitos podem se adaptar lentamente ou sofrerem alguma “mutação” enquanto os objetivos dos agentes se alteram. Há um processo de seleção pelo qual alguns hábitos e rotinas são perpetuados e imitados e outros, simplesmente, abandonados. Destarte, o que se verifica mais uma vez, é o caráter evolucionário e dinâmico do processo de mudança das estruturas sociais e econômicas, emergindo a necessidade de se combinar as teorias das escolas neo-schumpeteriana e neoinstitucionalista como forma de análise desse processo.

\section{CONSIDERAÇÕES FINAIS}

Como sugerido no presente texto há uma enorme agenda de pesquisa a ser mais bem compreendida, desenvolvida e concluída, a partir do estabelecimento de novos nexos conceituais entre o papel das instituições e do conhecimento tecnológico no desenho de novas trajetórias de crescimento e desenvolvimento econômico. Muito se avançou neste sentido ao longo das últimas duas décadas, mas pontos fundamentais permanecerem em aberto.

Em nossa visão, tais pontos somente serão preenchidos quando forem definidas de maneira mais precisa os nexos teóricos entre mudança tecnológica e mudança institucional. Os autores discutidos aqui propõem avanços neste sentido que remetem a uma nova ontologia econômica, que, partindo de uma redefinição geral do papel dos indivíduos, radicalmente diferentes dos agentes otimizadores e racionais do mainstream, incorporam desafios teóricos associados às noções de incerteza, racionalidade limitada e 
comportamentos idiossincráticos, os quais, por sua vez, estabelecem, de maneira interativa, novos ambientes às mutações tecnológicas e institucionais. E é somente dentro destes ambientes em mutação, que podemos desenhar novas e irreversíveis trajetórias de crescimento econômico, como o sugeriram as abordagens evolucionárias neoschumpeteriana e neo-institucionalista.

\section{REFERÊNCIAS}

ARTHUR, William Brian. Competing Technologies Increasing Returns and Lock-in by Historical Events. Economic Journal, 99, p.116-131., March, 1989.

CIMOLI, Mario; DOSI, Giovanni. De los Paradigmas Tecnológicos a los Sistemas Nacionales de Producción e Innovación. Revista Comercio Exterior, México, pp.669-682, Agosto, 1994.

COHEN, Wesley. M.; LEVINTHAL, Daniel. A. Absorptive Capacity: a new pespective on learning and innovation. Administrative Science Quarterly, 35, pp. 128-152, 1990.

CONCEIÇÃO, Octavio Augusto Camargo. Instituições, crescimento e mudança na ótica institucionalista. Porto Alegre: Teses FEE, 2002.

COSTA, A. B.D. Teoria Econômica e Política de Inovação. Texto para discussão n.

2015/14 PPGE/UFRGS. Programa de Pós-Graduação em Economia. Universidade Federal do Rio Grande do Sul. Disponível em: http://www.ufrgs.br/ppge/textos-para-discussao.asp (acesso 22/03/2016)

DOSI, Giovanni; NELSON, Richard, R. Technical Change and Industrial Dynamics as Evolutionary Processes. In.: HALL, Bronwyn H.; ROSENBERG, Nathan (eds.). Handbook of The Economics of Innovation. Volume 1. Oxford: Elsevier, 2010.

HODGSON, Geoffrey M. The Return of Institutional Economics. In: SMELSER,Neil J.; SWEDBERG, Richard (editors). The Handbook of Economic Sociology. New York: Princeton University Press, Princeton \& Russel Sage Foundation, 1994.

HODGSON, Geoffrey M. On the evolution of Thorstein Veblen's evolutionary economics. Cambridge Journal of Economics, vol. 22, p 415-431, 1998a.

HODGSON, Geoffrey M. The Approach of Institutional Economics. Journal of Economics Literature, vol. 36, p. 166-192, Mar., 1998b.

HODGSON, Geoffrey M. Economics and Uthopia: Why the learning economy is not the end of history. London: Routledge, 1999.

HODGSON, Geoffrey M. What are Institutions? Journal of Economic Issues, vol. XL, $\mathrm{n}^{\mathrm{o}}$ 1, pp. 1-25., Mar., 2006

METCALFE, John Stanley. Institutions and Progress. Industrial and Corporate Change, vol. 10, $\mathrm{n}^{\circ}$ 3, pp.561-586, 2001.

NELSON, Richard R. Bringing institutions into evolutionary growth theory. Journal of Evolutionary Economics, vol. 12, pp.17-28, 2002.

NELSON, Richard R..; WINTER, Sidney. Uma Teoria Evolucionária da Mudança Econômica. Campinas: Editora da Unicamp, 2005.

NELSON, Richard R. As Fontes do Crescimento Econômico. Campinas: Editora da Unicamp, 2006.

NELSON, Richard R. What enables rapid economic progress: What are the needed institutions? Research Policy, 37, pp. 1-11, 2008.

NORTH, Douglas. C. Institutions, Institutional Change and Economic Performance. Cambridge: Cambridge University Press, 1990.

ROMER, P. M. (1990). Endogenous Technological Change. Journal of Political Economy, Vol. 98, n. 5, pp. 71-102.

ROSEMBERG, Nathan. Por dentro da caixa-preta: tecnologia e economia. Campinas: Unicamp, 2006. 
RUTHERFORD, Malcolm. Veblen's evolutionary programme: a promise unfulfilled. Cambridge Journal of Economics, vol.22., pp. 463-477, 1998.

SAMUELS, Warren. The Presente State of Institutional Economics. Cambridge Journal of Economics, vol.19, pp.569-590, 1995.

SCHUMPETER, Joseph Alois. A Teoria do Desenvolvimento Econômico. São Paulo: Abril Cultural, 1982. (Coleção Os Economistas).

SCHUMPETER, Joseph Alois. A. Capitalismo, Socialismo e Democracia. Rio de Janeiro: Zahar, 1984.

SIMON, Herbert (1986). Rationality in Psychology and Economics. The Journal of Business, Vol. 59, No. 4, Part 2: The Behavioral Foundations of Economic Theory, pp. 209-224, Oct., 1986.

STANFIELD, James Ronald. The Scope, Method, and Significance of Original Institutional Economics. Journal of Economics Issues. v. XXXIII, n.2, 1999, p.231-255, june, 1999.

VEBLEN, Thorstein. Bunde. A Teoria da Classe Ociosa: um estudo econômico das instituições. São Paulo: Livraria Pioneira, 1965. (Coleção Biblioteca Pioneira de Ciências Sociais).

WILLIAMSON, Oliver. E. The New Institutional Economics: taking stock, looking ahead. Journal of Economic Literature. Vol. XXXVIII, pp. 595-613, Sep., 2000.

ZYSMAN, John. How Institutions Create Historically Rooted Trajectories of Growth. Industrial and Corporate Change, n.3, vol.1, pp.243-283, 1994. 